\title{
Ubiquitin Carboxyl-Terminal Hydrolase 14
}

National Cancer Institute

\section{Source}

National Cancer Institute. Ubiquitin Carboxyl-Terminal Hydrolase 14. NCI Thesaurus. Code C132092.

Ubiquitin carboxyl-terminal hydrolase 14 (494 aa, $~ 56 \mathrm{kDa}$ ) is encoded by the human USP14 gene. This protein is involved in the regulation of both ubiquitinated protein degradation and endoplasmic reticulum-associated degradation. 